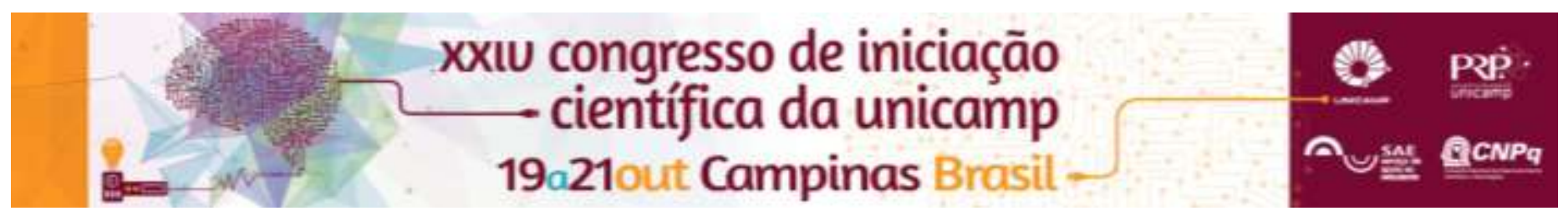

\title{
Eletrodos de Difusão Gasosa contendo semicondutores para redução fotoeletrocatalítica de $\mathrm{CO} 2$
}

\author{
Giuvanni Mutton*, Miguel T. Galante, Raul S. Figueiredo, Rodnei Bertazzoli, Cláudia Longo
}

\section{Resumo}

O aumento nas emissões de $\mathrm{CO} 2$ tem motivado a comunidade científica a buscar métodos que convertam este gás de efeito estufa a produtos de maior valor agregado. Com esta motivação, estamos investigando eletrodos de difusão gasosa modificados com um óxido misto de tungstato de bismuto e prata (EDG-HTS-AgBiW-ox); a presença do fotocatalisador não alterou a permeabilidade do EDG ao CO2 e em solução aquosa de imidazol e sob fluxo contínuo de $\mathrm{CO} 2$, a irradiação com um simulador solar intensificou a corrente catódica. Os resultados indicam que o EDG-HTSAgBiW-ox pode ser considerado um fotocatodo promissor para produção de "solar fuels" através da redução do $\mathrm{CO} 2$.

\section{Palavras-chave:}

eletrodos de difusão gasosa, redução de CO2, fotoeletroquímica

\section{Introdução}

A preocupação da comunidade científica em buscar alternativas para reduzir a quantidade liberada de $\mathrm{CO}_{2}$ para a atmosfera, ou para reaproveitá-lo, convertendo este gás de efeito estufa a produtos de maior valor agregado, tem se intensificado nos últimos anos. A redução eletroquímica do $\mathrm{CO}_{2}$ a metanol e ácido fórmico envolve valores muito intensos de potencial; resultados interessantes foram obtidos em líquido iônico, ${ }^{[1]} \mathrm{em}$ meio aquoso utilizando eletrodos de difusão gasosa (EDG), ${ }^{[2]}$ e ainda em solução aquosa de imidazol com eletrodos semicondutores sob irradiação. ${ }^{[3]}$ Em nosso Grupo de Pesquisa, estamos obtendo resultados promissores com um óxido misto de tungstato de bismuto e prata obtido por síntese hidrotérmica (HTS-AgBiW-ox); neste projeto, estamos desenvolvendo EDG modificado com este semicondutor para aplicação como fotocatodo na redução fotoeletrocatalítica do $\mathrm{CO}_{2}$.

\section{Resultados e Discussão}

Amostras de EDG (diâmetro $10 \mathrm{~mm}$, espessura $2 \mathrm{~mm}$ ), foram preparadas por prensagem de pigmento grafítico e politetrafluoroetileno a $300{ }^{\circ} \mathrm{C}$; a seguir, depositou-se um filme de partículas do fotocatalisador. $O$ eletrodo resultante, EDG-HTS-AgBiE-ox, apresentou constantes de permeabilidade de 0,8 a 1,1 md para os gases $\mathrm{CO}_{2} \mathrm{e}$ $\mathrm{N}_{2}$. Estes valores são similares aos apresentados por EDG em estudos anteriores, ${ }^{[2]}$ indicando que 0 fotocatalisador depositado não obstruiu a porosidade destes eletrodos. As propriedades eletroquímicas foram avaliadas em uma célula adequada, com pressão de $\mathrm{CO}_{2}$ de $0,07 \mathrm{kgf} / \mathrm{cm}^{2}$, em solução aquosa $0,1 \mathrm{M}$ de $\mathrm{Na}_{2} \mathrm{SO}_{4}$ e $20 \mathrm{mmol} / \mathrm{L}$ de imidazol. A Figura 1 apresenta a curva de cronoamperometria obtida sob polarização a $-0,35 \mathrm{~V}$ ( $\mathrm{vs} \mathrm{Ag} / \mathrm{AgCl}$ ) e, como detalhe inserido, os voltamogramas cíclicos $(20 \mathrm{mV} / \mathrm{s})$ registrados em iluminação ambiente e sob irradiação com um simulador solar. Sob irradiação, o EDG-HTS-AgBiW-ox apresentou fotocorrente catódica, indicando comportamento de semicondutor tipo-p. A intensificação da corrente catódica pode ser atribuída à interação entre elétrons fotogerados na superfície do semicondutor HTS-AgBiWox com o imidazol, um aceptor de elétrons que forma um complexo com o $\mathrm{CO}_{2}{ }^{[3]}$

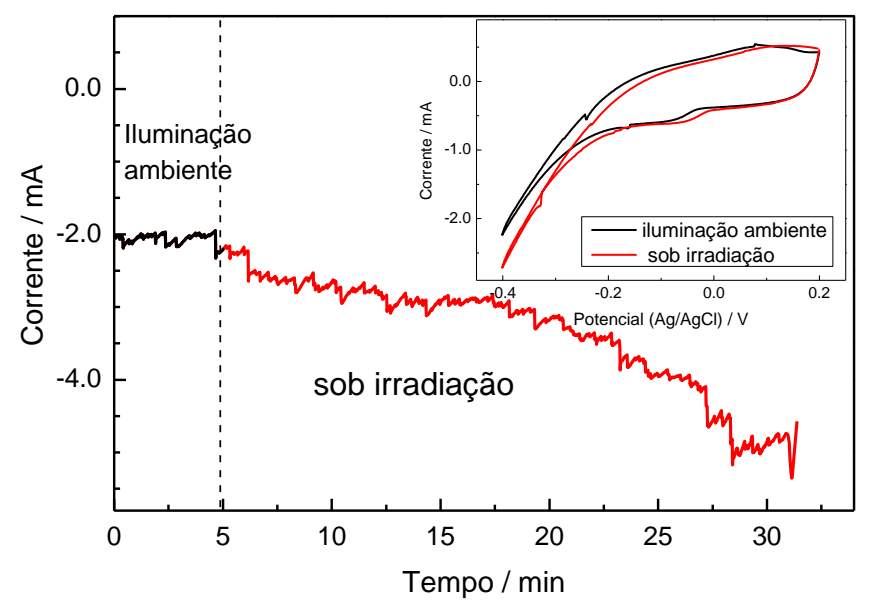

Figura 1. Eletrodo de difusão gasosa modificado com um semicondutor em solução aquosa $0,1 \mathrm{M}$ de $\mathrm{Na}_{2} \mathrm{SO}_{4} \mathrm{e}$ $20 \mathrm{mM}$ de imidazol, sob fluxo de $\mathrm{CO}_{2}$ : variação da corrente sob polarização a $-0,35$ V (vs $\mathrm{Ag} / \mathrm{AgCl}$ ) e voltamogramas cíclicos $(20 \mathrm{mV} / \mathrm{s})$ em iluminação ambiente e sob irradiação com simulador solar.

\section{Conclusões}

A deposição de um óxido misto de tungstato de bismuto e prata não alterou a permeabilidade do eletrodo de difusão gasosa ao $\mathrm{CO}_{2}$. O eletrodo resultante, EDGHTS-AgBiW-ox, em solução aquosa de imidazol e sob fluxo contínuo de $\mathrm{CO}_{2}$, apresentou corrente catódica intensificada sob irradiação com um simulador solar. Os estudos realizados revelam que o EDG-HTS-AgBiW-ox pode ser considerado um fotocatodo promissor para redução fotoeletrocatalítica de $\mathrm{CO}_{2}$.

\section{Agradecimentos}

CNPq, CAPES, FAPESP e INOMAT.

[1] N. Hollingsworth, S. F. Rebecca Taylor, M.T. Galante, J. Jacquemin, C. Longo, K.B. Holt, N.H. de Leeuw, C. Hardacre, Angewandte Chemie, 2015, 54,4164 .

[2]. Ferreira, L. H.. Eletrorredução de $\mathrm{CO}_{2}$ para geração de metanol, etanol e ácido fórmico. Tese de doutorado. FEM, UNICAMP, 2011

[3] Bocarsly, A. B, Gibson, Q. D, Morris, A. J, L'Esperancer R. P, Detweiler, Z. M, Lakkaraju, P. S, Zeitler, E. L, Shaw, T. W. ACS Catal, 2, 2012, 1684. 